\title{
Silver Nanoparticles Synthesis in a Green Approach: Size Dependent Catalytic Degradation of Cationic and Anionic Dyes
}

\section{SHUJIT CHANDRA PAUL ${ }^{*}$, SNAHASISH BHOWMIK ${ }^{1}$, MITHUN RANI NATH ${ }^{1}$, MD. SHAFIUL ISLAM ${ }^{1}{ }^{12}$, SAURAV KANTI PAUL ${ }^{1}$, JAHRUN NEAZI ${ }^{1}$, TANIA SABNAM BINTA MONIR ${ }^{1}$, SANCHITA DEWANJEE ${ }^{1}$ and MOHAMMED ABDUS SALAM ${ }^{3}$}

\author{
${ }^{1}$ Department of Applied Chemistry and Chemical Engineering, Noakhali Science and Technology \\ University, Bangladesh. \\ 2Department of Chemistry, Virginia Commonwealth University, Richmond, United States of America. \\ ${ }^{3}$ Department of Environmental Science and Disaster management, Noakhali Science and Technology \\ University, Bangladesh. \\ *Corresponding author E-mail: shujitchandrapaul@gmail.com
}

http://dx.doi.org/10.13005/ojc/360301

(Received: May 02, 2020; Accepted: June 05, 2020)

\begin{abstract}
Green synthesis of nanoparticles is more preferable because of its flexibility in preparation as well as its capability to avoid utilization of toxic chemicals. This study was designed to synthesize silver nanoparticles from plant leaves of Calendula officinalis for utilizing it for the degradation of commonly used dyes. The maximum absorption of UV-Vis light at $436 \mathrm{~nm}$ ensured the synthesis of silver nanoparticle. The various reducing agent present in plant leaves extract cause the formation of silver nanoparticles as ensured by the FTIR. The morphology study showed that the synthesized nanoparticles were $50-60 \mathrm{~nm}$ and $140-150 \mathrm{~nm}$ in size for $1 \mathrm{mM}$ and $2 \mathrm{mM}$ silver nanoparticles (Ag NPs) respectively. It has also been observed that the synthesized nanoparticles possess a high catalytic activity for the degradation of both methylene blue and methyl orange. The degradation data ensured that the reaction rate of degradation is size dependent and the highest degradation percentage $\left(69.79 \%\right.$ within 5 minutes), degradation rate $\left(0.18 \pm 0.03 \mathrm{~min}^{-1}\right)$, half-life $\left(T_{50}=3.85 \mathrm{~min}\right)$ and $80 \%$ degradation $\left(\mathrm{T}_{80}=8.94 \mathrm{~min}\right.$ ) was observed for $1 \mathrm{mM} \mathrm{Ag} \mathrm{NPs}$ in case of methyl orange.
\end{abstract}

Keywords: Silver nanoparticles, Calendula officinalis, Green-synthesis, Degradation, Methylene blue, Methyl orange.

\section{INTRODUCTION}

Safe sources of surface water are important for human civilization because quality water is a vital element of our human life, environment, agricultural and industrial activities etc. ${ }^{1}$. However, with development of industrial sectors, like textile and paper industry, water is being polluted massively in the last few decades due to the release of various organic dyes from these industries to the various water sources ${ }^{2,3}$. These industrial grade dyes are so harmful to the environment particularly for the

This is an Open Access article licensed under a Creative Commons license: Attribution 4.0 International (CC- BY). Published by Oriental Scientific Publishing Company @ 2018

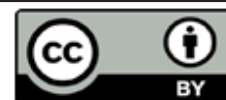


water body because of its toxicity and carcinogenic nature ${ }^{4}$. Although, a number of methods are already used for removal of dye from water body, such as ion exchange, ozonation, UV radiation etc, however they are not considered as prominent because of their high cost and complexity ${ }^{5,6,7}$. Nowadays, as compared to the traditional technology, nanotechnology is considering as an effective technology due to its ability for fast and effective removal of dyes from water sources.

Nanotechnology deals with synthesis of nanomaterials which are being used for the welfare of human civilization ${ }^{8}$. Nanomaterials is one of the most widely used materials globally due to its unique physical, chemical and biological properties. Such variation in properties make it usable in the field of catalysis, biology, electronics etc. ${ }^{9,10}$. Among various nanomaterials, like gold or zinc oxide, silver nanoparticles are most preferable for processing and manufacturing because of its cost effectivity, stability and abundancy ${ }^{1}$.

Although physical and chemical methods are most widely used for silver nanoparticle synthesis, but both method expensive, time consuming and sometimes utilization of hazardous chemical make them unusable in various field of study ${ }^{11}$. Therefore, in the recent time, green synthesis of silver nanoparticle is mostly practicing in nanoparticle synthesis because in this process plant extract from various plants are used as both reducing and capping or stabilizing agent ${ }^{12}$. In addition, as compared to the activity of chemically synthesized nano catalyst, plant extract-based nanoparticles might possess additional catalytic activity due to the presence of plant biomolecules on the nanoparticle surface which may increase the reaction rate of chemical reaction ${ }^{13}$. The various chemicals like terpenoids, polyphenols, flavonoids, phenolic acids, found in plant extract are responsible for reduction silver ions and formation of stabilized nanoparticles within a very short time ${ }^{13}$. Till now a wide number of studies was undertaken for green synthesis of silver nanoparticles from various parts of plant like, seeds of $T$. foenum-graecum ${ }^{14}$, fruits of Sterculia acuminate ${ }^{15}$, leaves of Morinda tinctoria $\beta$ and leaf broth of Azadirachta Indica ${ }^{16}$ for the degradation of various organic dyes and textile effluents.

The aim of this study was to synthesize the silver nanoparticles through the faster and eco-friendly green routes by using leaf extract of Calendula officinalis for studying its catalytic efficiency for the degradation of most commonly used cationic and anionic dyes.

\section{MATERIALS AND METHODS}

\section{Materials}

Silver nitrate (99.8\% pure) was purchased from Yingdashiji, Japan, Sodium borohydride (98\%) from Dae-Jung, Korea, methyl orange (MO) and methylene blue (MB) were purchased from Merck (India). Deionized water was used for preparation of solution without further purification of reagents. Plant leaves were collected from Noakhali Science and Technology University campus premises.

\section{Perpetration of plant extract}

The plant extract was prepared by collecting fresh leaves Calendula officinalis from garden which were then rinsed three to four times with deionized water to remove debris, and finally dried in air at ambient temperature. Then approximately $20 \mathrm{~g}$ of dry leaves were taken for heating in exactly $100 \mathrm{~mL}$ of deionized water for about $60 \mathrm{~min}$ at $80^{\circ} \mathrm{C}$. The slightly yellow colour extract is then filtered through Whatman filter paper No. 41 to remove any particles. The pale-yellow clear solution was then collected and stored at $4-8^{\circ} \mathrm{C}$ for further utilization.

\section{Synthesis of $\mathrm{Ag}$ nanoparticles (Ag NPs)}

The desired Ag NPs was synthesized by using silver nitrate $\left(\mathrm{AgNO}_{3}\right)$ salt (Merck, Germany) and Calendula officinalis leaf extract, which act as both reducing and capping agent. For the synthesis, we prepare the silver nitrate solution at different concentration ( $1 \mathrm{mM}$ and $2 \mathrm{mM}$ ) and mixed it with extract at a ratio of 9:1. The mixture was then allowed to stir at $200 \mathrm{rpm}$ for exactly 1 hours. The formation of Ag NPs was confirmed by a colour change from pale yellow to brown. The as synthesize nanoparticles were then washed with water, centrifuged at 8,000 rpm for $10 \mathrm{~min}$, dried and stored for further analysis.

\section{Characterization}

UV-Visible analysis was done at a range of 200-700nm wavelength at same condition by using Shimadzu UV-1800 UV-Visible spectrophotometer. Deionized water was used for background correction of all the absorption data. FTIR spectra of the synthesized nanoparticles sample and extract were recorded using IR Prestige-21 Shimadzu spectrometer. The crystal structure of silver nano particles was done by XRD analysis which was performed by using CuK $\alpha 1$ radiation in the region of 20-90 degree 
by Bruker's D 8-Discover X-ray diffractometer. The surface morphology of the silver nanoparticles was examined by using JEOL JSM-7600F Field Emission Scanning Electron Microscope with EDS.

\section{Catalytic degradation study}

The degradation study was based on using silver nanoparticles as catalyst for two different dyes like methylene blue (MB) and methyl orange (MO). 2.5 $\mathrm{mg}$ of Ag NPs was added in a $20 \mathrm{~mL}$ of $40 \mathrm{ppm}$ dye solution. Subsequently about $0.5 \mathrm{~mL}$ of $0.1 \mathrm{M} \mathrm{NaBH}_{4}$ solution was added to the mixture with stirring. The Degradation of dye was ensured by discoloration and the concentration study were performed by using an UV-Vis spectrophotometer in the range of 500-700 $\mathrm{nm}$ for MB and 350-550nm for MO at different time intervals. All the catalytic reactions were performed at room temperature. The percentage of degradation (\%) at a particular time and time required for $50 \%$ and $80 \%$ degradation of dyes $\left(\mathrm{T}_{50}\right.$ and $\left.\mathrm{T}_{80}\right)$ were calculated by the following equations.

$\%$ of degradation $=\frac{A_{0}-A_{t}}{A_{0}} \times 100$

$T_{50}=\frac{0.693}{k}$

$T_{80}=\frac{1.609}{k}$

Where, $A_{0}$ and $A_{t}$ and $k$ are the initial absorbance, absorbance at time t and rate constant respectively.

\section{RESULTS}

\section{UV-Vis spectra analysis}

The UV-Visible absorption spectra of the green synthesized Ag nanoparticles with different concentrations and plant extract are shown in Fig. 1. The formation of nanoparticles was assured visually by a change in colour form almost colourless to dark brown. Usually the free electron of metal nanoparticles leads to the formation of surface plasmon resonance (SPR) absorption band at a definite wavelength of UV-Visible light. In our study we observed the peak at exactly $436 \mathrm{~nm}$ for both the concentration variation as observed by other study ${ }^{17}$. The higher absorbance value of $2 \mathrm{mM}$ sample assured that more nanoparticles were formed in this case as compared to the $1 \mathrm{mM}$ sample for the same amount of plant extract. The broad peak for plant extract was observed because the plant extract was itself coloured while extracted from plant leaves.

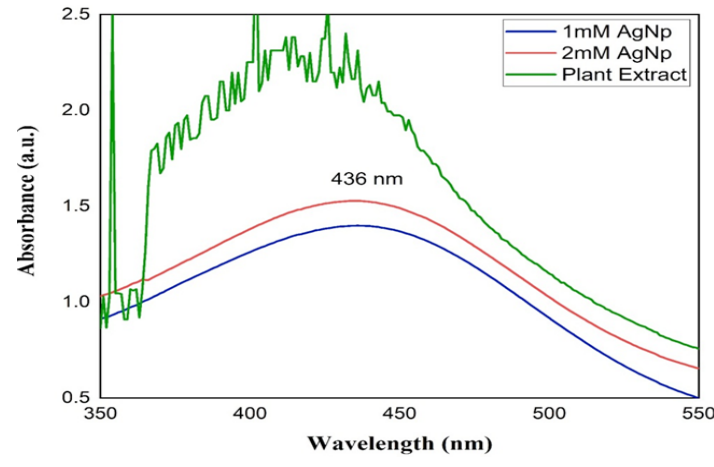

Fig. 1. UV-Vis spectra of plant leaves extract and Ag NPs colloidal suspension

\section{FTIR study}

The FTIR analysis was carried out to identify major functional groups present in the Calendula officinalis leaf extract, which are responsible for the synthesis of Ag NPs. These functional groups might be responsible for the reduction of silver ions to silver nanoparticles. The FTIR spectrum of marigold leaf extract revealed the presence of sharp absorption peaks at 665, 1635 and $3438 \mathrm{~cm}^{-1}$ (Fig. 2). The peak at $1635 \mathrm{~cm}^{-1}$ was due to strong stretching vibrations of carbonyl group of $\alpha, \beta$-unsaturated compounds of leaf extract. The broader peak at $3338 \mathrm{~cm}^{-1}$ indicated the presence of $\mathrm{OH}$ stretching in flavonoids, xanthonoids and phenolic compounds- which are considering as the main reducing agent for silver ions. The shift from higher (in extract) to lower (in Ag NPs) frequency of $\mathrm{OH}$ stretching is attributed to the reduction of silver ions $\left(\mathrm{Ag}^{+}\right)$by $\mathrm{OH}$ based products present in leaves ${ }^{18,19}$.

$$
\mathrm{R}-\mathrm{O}-\mathrm{H}+\mathrm{Ag}^{+}\left(\mathrm{AgNO}_{3}\right) \rightarrow \mathrm{Ag}^{\mathrm{O}}
$$

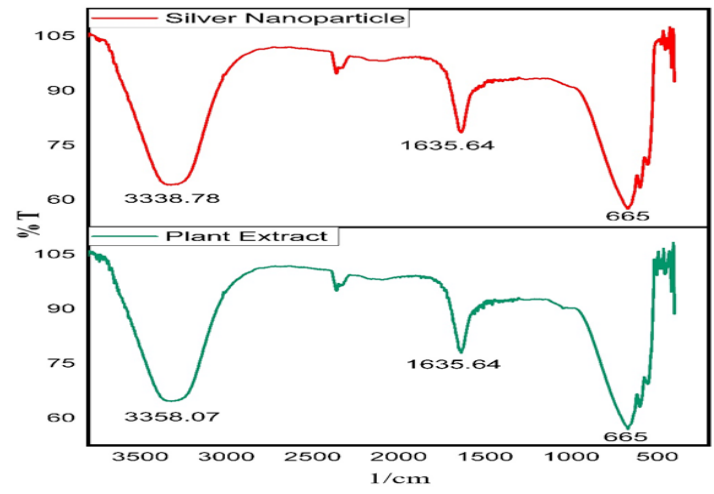

Fig. 2. FTIR of both silver nanoparticles and plant extract

\section{Morphology Analysis}

The morphology study was conducted by SEM analysis as shown in Fig. 3(a-b). Form the analysis it is very clear that Ag NPs synthesized by $1 \mathrm{mM}$ silver precursors are more uniform and spherical in nature as compared to the $2 \mathrm{mM}$ solution. 

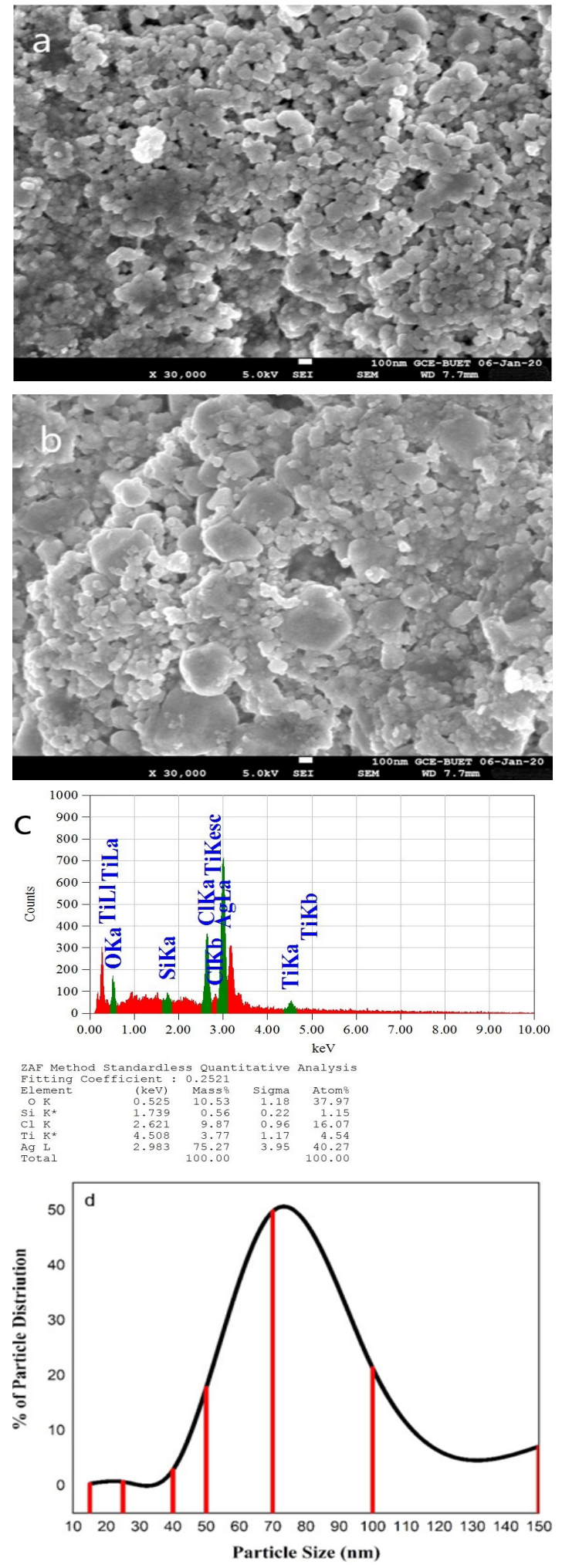

Fig. 3. (a-b) SEM images of $1 \mathrm{mM}$ and $2 \mathrm{mM}$ Ag NPs (c) EDS data; (d) particle size distribution of synthesized 1mM AgNPs
The average size of the nanoparticles was 50-60 $\mathrm{nm}$ and $140-150 \mathrm{~nm}$ for $1 \mathrm{mM}$ and $2 \mathrm{mM}$ solution respectively Fig. $3 \mathrm{~d}$. In case of $2 \mathrm{mM}$ silver precursor some agglomeration of NPs was observed which might be due to the fact that the stabilizing agent present in the plant extract was not much enough for $2 \mathrm{mM}$ solution resulting in agglomeration and enlarged the particle sizes. However, the difference in particle size in different regions of the same sample might be due to the different reducing agents present in the plant extract $^{20}$. The EDX data ensured the presence of $\mathrm{Ag}$ and give a strong signal at $3 \mathrm{KeV}$. The data also showed that, the two major elements are silver $(75.27 \%$ by mass) and oxygen (10.53\% by mass). However, the presence of impurities like $\mathrm{Si}$, Ti might be due to the copper grid used during analysis Figure. 3c.

\section{XRD Analysis}

The XRD data of o the synthesized $1 \mathrm{mM}$ $\mathrm{Ag}$ NPs is shown in Fig. 4. The peaks at position of $38.140,44.360,64.440,77.460,81.620$ representing the diffraction planes (111), (200), (220), (311), (222) respectively of the face centred silver nanoparticles (JCPDS file No. 87-0720). The average crystal size of the synthesized nanoapertures were calculated by the following equation (4).

$$
D=\frac{k \lambda}{\beta \cos \theta}
$$

and the average crystal size was $14.37 \mathrm{~nm}$ ensuring the formation of naocrystals, where 0.9 is the shape factor $(\mathrm{k}), \lambda$ is the wavelength from CuK $\alpha 1$ radiation (typically $1.54^{\circ} \mathrm{A}$ ), $\beta$ is the FWHM (radians) and $\theta$ is the Bragg angle of diffraction.

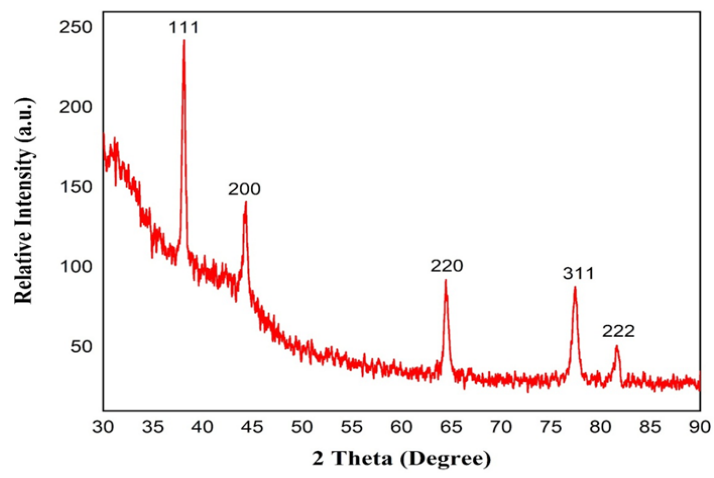

Fig. 4. The X-ray diffraction pattern of bio-synthesized silver nanoparticles

\section{Degradation study of Methylene Blue}

The degradation of dye by Ag NPs is well documented because of its unique physical and chemical properties ${ }^{21}$. Ag nanoparticles are the stable catalysts which are used to degrade both organic compounds and dyes. In case of the degradation 
of dye, the catalytic activity of green synthesized silver nanoparticles along with $\mathrm{NaBH}_{4}$ has been manifested earlier with the use of methylene blue at room temperature ${ }^{16,22}$. Time plays an important role in order to assess the degradation of MB. In this regard, the relative absorbance of band at $664 \mathrm{~nm}$ is devised as a function of time ${ }^{15}$. The degradation was monitored by UV-Vis spectrophotometry as well as by visual inspection of the color change from initial dark blue MB to almost colourless. The Fig. (5a) shows that the absence of Ag nano catalysts does not exhibit any remarkable change in shifting the peak position for methylene blue solution for a longer period of time, far exceeding 1 to 120 min. When silver nanoparticles were added, the absorbance of dye is lessened with lesser reaction time in comparison with their absence.
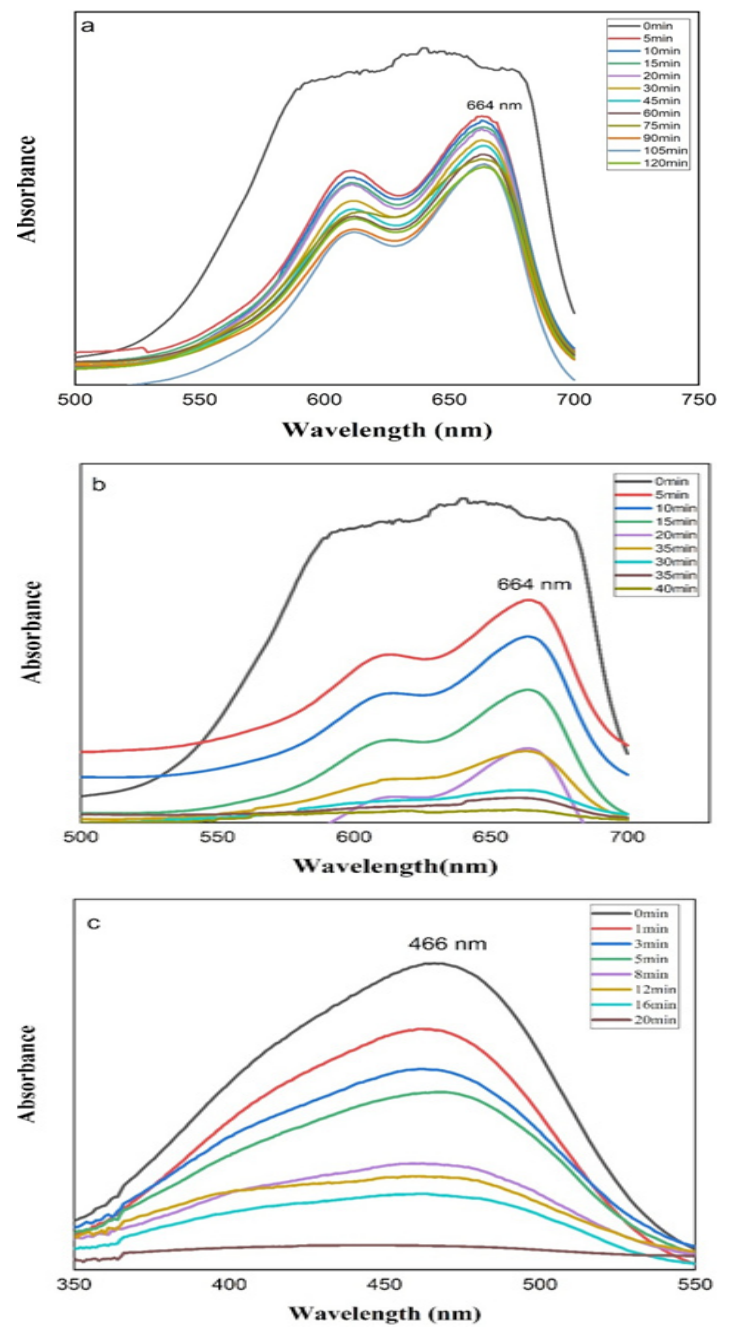

Fig. 5. UV-Visible absorption spectra of degradation of methylene Blue by $\mathrm{NaBH}_{4}$ in the (a) absence of silver nanoparticles (b) presence of $1 \mathrm{mM}$ silver NP (c) presence of $2 \mathrm{mM}$ silver NP
This phenomenon assured that the Ag NPs act as a catalyst to escalate the reaction. The result of the relative absorption intensity with wavelength in a regular interval of time $(5 \mathrm{~min})$ showed that the whole degradation process of $\mathrm{MB}$ has been completed within $40 \mathrm{~min}$ in the presence of $1 \mathrm{mM}$ silver nanoparticles and it took about $60 \mathrm{~min}$ for $2 \mathrm{mM}$ Ag NPs indicating that $1 \mathrm{mM}$ Ag NPs showed faster degradation and higher removal efficiency (Fig. $5 b$ and 5c). The percentage of degradation of MB for different Ag NPs vary significantly, for instance, in case of $1 \mathrm{mM}$ silver nano catalysts about $50 \%$ degradation of $\mathrm{MB}$ is taken place in about 9 min only whereas it takes about 23 min for same degradation $2 \mathrm{mM}$ silver nano catalysts (Table 1 ). Most surprisingly $80 \%$ of the degradation reached in about 20.12 min for $1 \mathrm{mM}$ NPs although it took about $53 \mathrm{~min}$ for the same quantity of degradation.

Table 1: Comparison of degradation kinetics of dye solution by bio-synthesized AgNp

\begin{tabular}{lccc}
\hline $\begin{array}{l}\text { Nanoparticle } \\
\text { Catalyst }\end{array}$ & Parameters & Methylene Blue & Methyl Orange \\
\hline \multirow{2}{*}{ 1mM Ag Np } & Rate constant & $0.08 \pm 0.006$ & $0.18 \pm 0.03$ \\
& $(\mathrm{k})\left(\mathrm{min}^{-1}\right)$ & & \\
& Time (min) & 5 & 5 \\
& Degradation (\%) & 27.12 & 69.79 \\
& T50 (min) & 8.66 & 3.85 \\
& T80(min) & 20.12 & 8.94 \\
2mM Ag Np & Rate constant & $0.03 \pm 0.003$ & $0.11 \pm 0.01$ \\
& (k) (min $\left.{ }^{-1}\right)$ & & \\
& Time (min) & 5 & 5 \\
& Degradation (\%) & 18.08 & 42.11 \\
& T50 (min) & 23.1 & 6.3 \\
T80(min) & 53.66 & 14.63 \\
\hline
\end{tabular}

\section{Degradation Study of Methyl Orange}

The reduction of organic dyes by excess of $\mathrm{NaBH}_{4}$ is largely used for evaluating the catalytic efficiency of metal nanoparticles ${ }^{2}$. MO is an organic sulfosalt dye, which can be reduced by reductants like $\mathrm{NaBH}_{4}$ to form small organic molecules and nontoxic species respectively although the reduction rate is very slow.

Metal nanoparticles with high reactive activity and specific surface area can accelerate the reduction rate of dyes. The aqueous solution of methyl orange shows strong absorptions UV-Visible spectrum at $466 \mathrm{~nm}$ (Fig. 6a-6c). The maximum intensity at $466 \mathrm{~nm}$ is may be due to the absorption of azo group. The reduction of methyl orange by $\mathrm{NaBH}_{4}$ in the absence of silver nanoparticles catalyst is 
extremely slow. This is evident from the observation (Fig. 6a) that the intensity at $466 \mathrm{~nm}$ remains almost unchanged for several hours when a blank experiment is carried out without any silver nanoparticle addition. But the degradation reaction started readily upon the addition of silver nanoparticles as catalyst. After adding silver nanoparticles (Fig. 6b) to the $\mathrm{MO}$ and $\mathrm{NaBH}_{4}$ solution, adsorption can take place between the well-dispersed silver nanoparticles and $\mathrm{MO}$ molecules. The reaction was completed in $8 \mathrm{~min}$ for $1 \mathrm{mM}$ Ag NPs (Fig. 6b) and in 20 min for $2 \mathrm{mM} \mathrm{Ag} \mathrm{NPs}$ (Fig. 6c) as was evident from almost zero absorption at $466 \mathrm{~nm}$. Form table it is clear that about $80 \%$ of the dye was degraded within $8.94 \mathrm{~min}$ in case of $1 \mathrm{mM}$ ag NPs which is almost half of the time required for $2 \mathrm{mM}$ Ag NPs for the same quantity degradation.
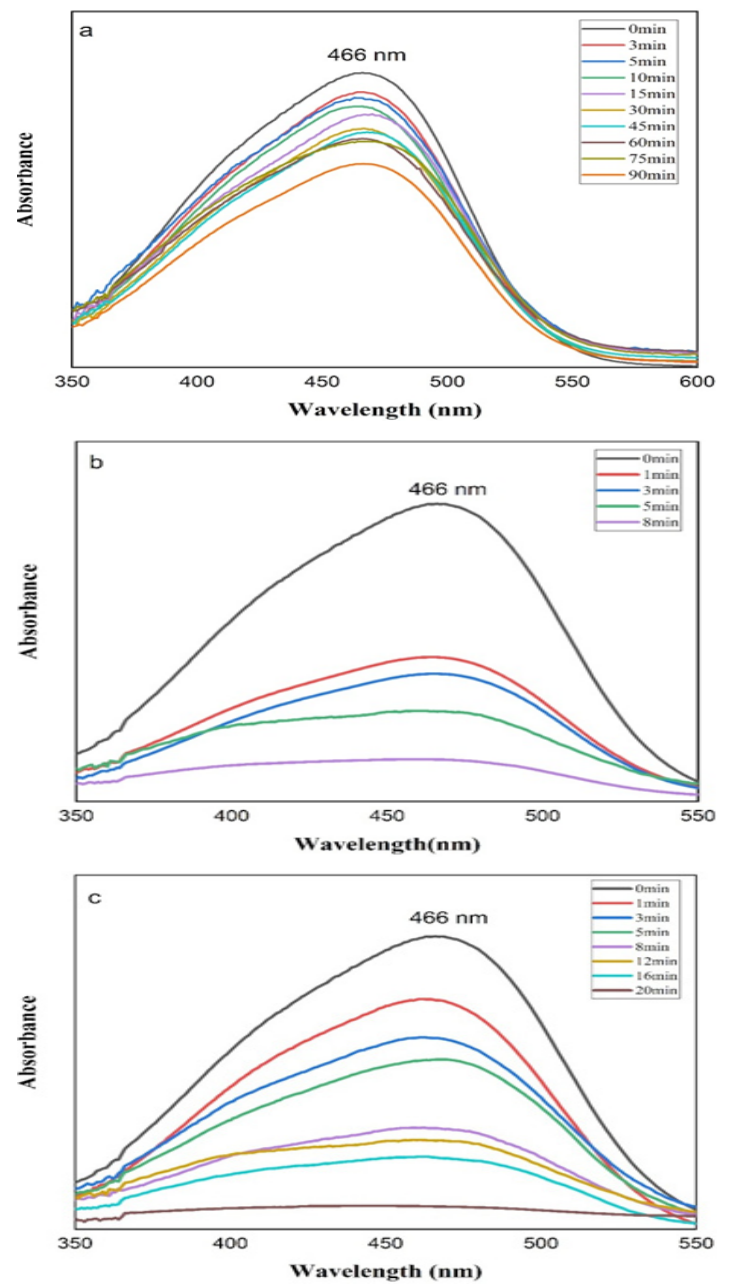

Fig. 6. UV-Visible absorption spectra of degradation of methyl orange by $\mathrm{NaBH}_{4}$ in the (a) absence of silver nanoparticles (b) presence of $1 \mathrm{mM}$ silver NP (c) presence of $2 \mathrm{mM}$ silver NP

\section{Kinetics of Dye degradation}

Metal nanoparticles act as catalyst for dye degradation by facilitating smooth electron transfer from donor to the acceptor. Before starting the degradation, the acceptor and donor materials get adsorbed on nanomaterials surfaces and get accelerate the degradation process through electron transfer reaction ${ }^{23}$. Thus, it can be said that, in all the catalytic reactions, silver nanoparticles act as an efficient catalyst through the electron transfer process. Fig. 7 showed the pseudo-first order kinetics of the reduction reaction of both methylene blue and methyl orange as catalysed by the biosynthesized AgNPs from plant extract. In both cases, a first-order reaction was applied according to the equation In $\left(A_{t} / A_{0}\right)=-k t$, where $A_{0}$ and $A_{t}$ represents the absorbance value of dye at time $t$ and at the initial state and $k$ is the rate constant of the reduction reaction. The rate constant $(k)$ was obtained by plotting In $\left(A_{t} / A_{0}\right)$ against the reaction time $t$ as shown in Figure. From the Fig. 7 and Table 1 it is clear that, the degradation rate of both the dyes are size dependent. The highest reaction rate was observed for methyl orange degradation and the rate constant value was about $0.18 \mathrm{~min}^{-1}$ for $1 \mathrm{mM}$ silver nanoparticle-based degradation.

In case of $\mathrm{MB}$ the highest degradation

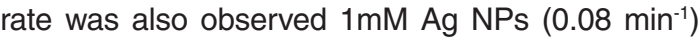
where as in case of $2 \mathrm{mM} \mathrm{Ag} \mathrm{NPs} \mathrm{it} \mathrm{was} \mathrm{only}$ $0.03 \mathrm{~min}^{-1}$. However, from Table 1 it is shown that, the degradation reached to its half value within $18 \mathrm{~min}$ for $\mathrm{MB}$ degradation by $1 \mathrm{mM} \mathrm{AgNp}$ and it takes about 6 min for degradation of $\mathrm{MO}$ by the same concentration of catalyst. Although the reaction conditions were kept same for both types dye degradation, but a difference in reaction rate was observed which might be due to the size variation of nanoparticles and the chemical structure of the target dye ${ }^{24}$.

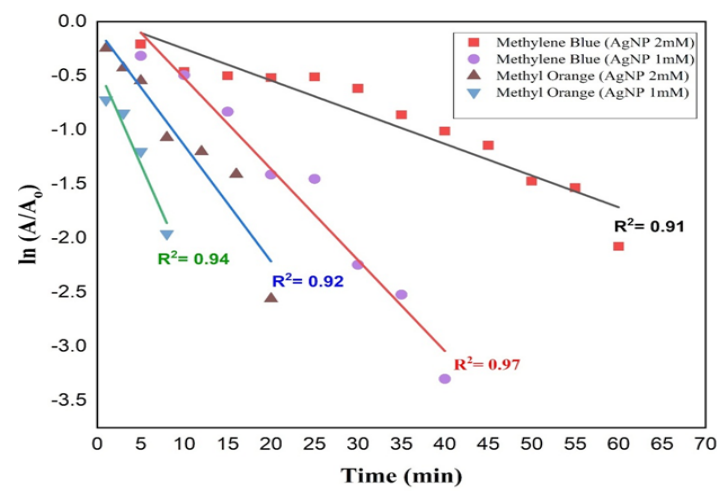

Fig. 7. The first order linear plot of $\ln \left(A_{t} / A_{0}\right) v s$. time of (a) methyl orange (b) methylene blue in the presence of silver nanoparticles as catalyst 


\section{DISCUSSIONS}

The silver NPs synthesised by the green approach showed an excellent catalytic activity against $\mathrm{MB}$ and $\mathrm{MO}$ degradation. The faster degradation of $\mathrm{MB}$ in the presence of $\mathrm{Ag} \mathrm{NPs}+$ $\mathrm{NaBH}_{4}$ (reducing agent) is due to the electron transfer between AgNPs, $\mathrm{NaBH}_{4}$ and MB/MO. At time of charging of AgNPs surface by coupling of reducing agent $\left(\mathrm{NaBH}_{4}\right)$, almost all the electrons gathered in AgNPs were released to the MB which act as electron acceptor. AgNPs function as electron relay point that contribute to receive or leave electrons alternatively ${ }^{24,25}$. Electron transfer plays the crucial role in the degradation of methyl orange also. The large difference in redox potential between the donor borohydride ion and the acceptor methyl orange hinders the electron transfer between them ${ }^{26}$. So, the large specific area of nanoparticles increases the reactivity. On the surface of silver nanoparticles there is a layer of reducing agent which may also promote the effective adsorption between silver nanoparticles and $\mathrm{MO}$ molecules. As a consequence, the oxidationreduction between the active $\mathrm{MO}$ and $\mathrm{NaBH}_{4}$ can take place with more ease and faster for particles with smaller size which is ensured by the reaction kinetics of $1 \mathrm{mM}$ and $2 \mathrm{mM}$ Ag NPs.

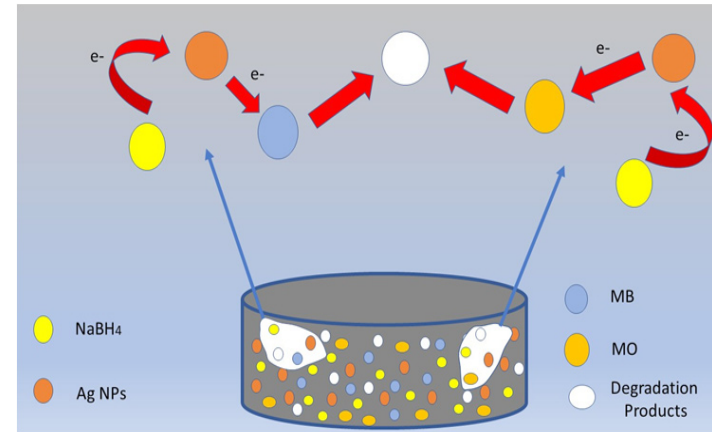

Fig. 8. degradation mechanism of dye by Ag NPs in presence of $\mathrm{NaBH}_{4}$

A comparison study on degradation of $\mathrm{MB}$ and $\mathrm{MO}$ by Ag NPs at different conditions is summarized in Table 2. From Table 2 it is clear that for the degradation of higher concentration of dye our as synthesised catalyst showed maximum activity as compared to other reports. For instance, a study of MB degradation (12 ppm) took about $360 \mathrm{sec}$ (6 min) for more than $95 \%$ degradation by $5 \mathrm{mg}$ of $\mathrm{Ag}$ NPs whereas Ag NPs in this took about 60 min for same quantity degradation of about $40 \mathrm{ppm}$ of dye ${ }^{28}$. Again, our as synthesised is more effective for MB degradation as compared to the photodegradation which took about 72 hours. for achieving the maximum degradation of $95 \%$.

Table 2: Comparison of degradation dye solution Ag NPs with previous studies

\begin{tabular}{|c|c|c|c|c|c|}
\hline Degradation Agents & Dye & $\%$ of degradation & Time & $\begin{array}{l}\text { Reaction } \\
\text { rate }(\mathrm{k})\end{array}$ & Reference \\
\hline Ag-PSTY-PNIPMA-ACC/NaBH4 (2.2mM) & Methylene Blue (0.02ppm) & $>95$ & $6 \mathrm{~min}$ & $0.625 \mathrm{~min}^{-1}$ & 27 \\
\hline \multirow[t]{2}{*}{ Ag NPs $(5 \mathrm{mg}) / \mathrm{NaBH} 4(0.1 \mathrm{M})$} & Methylene Blue & & & & \\
\hline & (12 ppm) & $>95$ & $360 \mathrm{sec}$ & $0.14 \mathrm{~s}^{-1}$ & 28 \\
\hline Ag NPs/Sunlight & Methylene Blue (10 ppm) & 95 & $72 \mathrm{~h}$ & - & 29 \\
\hline \multirow[t]{2}{*}{ Ag NPs/NaBH4 } & Methyl Orange & & & & \\
\hline & (0.02 ppm) & 97 & $5 \mathrm{~min}$ & $6.8 \times 10^{-3} \mathrm{~s}^{-1}$ & 30 \\
\hline \multirow[t]{2}{*}{ ZnO NPs/ sunlight } & Methylene Blue & & & & \\
\hline & (50 ppm) & 98 & 210 & $0.009 \mathrm{~min}^{-1}$ & 31 \\
\hline Ag NPs $(2.5 \mathrm{mg}) / \mathrm{NaBH} 4(0.1 \mathrm{M})$ & Methylene Blue (40 ppm) & $>95$ & $40 \mathrm{~min}$ & $0.08 \mathrm{~min}^{-1}$ & This study \\
\hline Ag NPs $(2.5 \mathrm{mg}) / \mathrm{NaBH} 4(0.1 \mathrm{M})$ & Methyl Orange (40 ppm) & $>95$ & $10 \mathrm{~min}$ & $0.18 \mathrm{~min}^{-1}$ & This study \\
\hline
\end{tabular}

\section{CONCLUSION}

From the study, we observed that a wellshaped silver nanoparticle was synthesized by using the leave extract of Calendula officinalis without using any other traditional and expensive reducing chemicals. The as synthesized nanoparticles possessed a high catalytic activity in the presence of $\mathrm{NaBH}_{4}$ for degradation of both methylene blue and methyl orange. Therefore, it can be concluded that, the synthesized nanoparticles can be used as a promising catalyst for the removal of organic pollutants like dye from water both efficiently and environmentally friendly way.

\section{ACKNOWLEDGEMENT}

The author thanks to the laboratory and 
staffs of Department of Applied Chemistry and Chemical Engineering, Noakhali Science and Technology University, Bangladesh, for providing all the facilities to carry out this study. The authors also like to give special thanks to Glass and Ceramics Engineering Dept. of Bangladesh
University and Engineering and Technology (BUET), Bangladesh, for their assistance in instrumental analysis.

\section{Conflicts of Interest}

The authors declare no conflict of interest.

\section{REFERENCES}

1. Sharma, K.; Singh, G.; Kumar, M.; Bhalla, V. RSC Adv., 2015, 5, 25781-25788.

2. Zhang, H.; Chen, D.; Lv, X.;Wang, Y.; Chang, H.;Li, J. Environ. Sci. Technol., 2010, 44(3), 1107-1111.

3. Martínez-Huitle, C.A.;Brillas, E. Applied Catalysis B: Environmental., 2009, 87, (4-5), 105-145.

4. Lellis, B.; Fávaro-Polonio, C. Z.; Pamphile, J. A.; Polonio, J. C. Biotechnol. Res. Innov., 2019, 3(2), 275-290.

5. Srivastava, V.; Choubey, A. K. Adv. Nat. Sci. Nanosci. Nanotechnol., 2019, 10, 045015

6. Yagub, M. T.; Sen, T. K.; Afroze, S.; Ang, H. M. Adv. Colloid Interface Sci., 2014, 209, 172-184.

7. Katheresan, V.; Kansedo, J.; Lau, S.Y. J. Environ. Chem. Eng., 2018, 6(4), 4676-4697

8. Vanaja, M.; Paulkumar, K.; Baburaja, M.; Rajeshkumar, S.; Gnanajobitha, G.; Malarkodi, C.; Sivakavinesan, M.; Annadurai, G. Bioinorg. Chem. Appl., 2014.

9. Peters, R. J. B.; Bouwmeester, H.; Gottardo, S.; Amenta, V.; Arena, M.; Brandhoff, P.; Marvin, H. J. P.; Mech, A.; Moniz, F. B.; Pesudo, L. Q.; Rauscher, H.; Schoonjans, R.; Undas, A. K.; Vettori, M. V.;Weigel, S.; Aschberger, K. Trends Food Sci Technol., 2016, 54, 155-164.

10. Iravani, S.; Korbekandi, H.; Mirmohammadi, S. V.; Zolfaghari, B. Res. Pharm. Sci., 2014, 9(6), 385-406.

11. Roy, A.;Bulut, O.; Some, S.; Mandal, A.K.;Yilmaz, M. D. RSC Advances., 2019, 9, 2673-2702.

12. Borase, H. P., Salunke, B.K., Salunkhe, R.B., Patil, C.D., Hallsworth, J.E., Kim, B.S., Patil, S,V. Appl. Biochem. Biotech., 2014, 173(1), 1-29.

13. Demirbas, A.; Yilmaz, V.; Ildiz, N.; Baldemir, A.; Ocsoy, I. J. Mol. Liq., 2017, 248, 1044-1049.

14. Dogru, E.; Demirbas, A.; Altinsoy, B.; Duman, F.; Ocsoy, I. J. Photochem. Photobiol. B Biol., 2017, 174, 78-83.

15. Vidhu, V. K.; Philip, D. Micron., 2014, 56, 54-62.

16. Bogireddy, N. K. R.; Kiran Kumar, H. A.; Mandal, B. K. J. Environ. Chem. Eng., 2016, 4(1), 56-64.

17. Nagar, N.; Devra, V. A. Heliyon., 2019, 5(3), e01356.
18. Kumari, R.M.;Thapa, N.; Gupta, N.; Kumar, A.; Nimesh, S. Adv Nat Sci Nanosci Nanotechnol., 2016, 7, 045009.

19. López-Miranda, J. L.; Cervantes-Chávez, J. A.; Hernández-Martínez, A. R.; Pérez, R., Esparza, R.; Estévez-González, M. Mat. Res. Exp., 2019, 6(6), 065066.

20. Latha, D.; Prabu, P.; Gnanamoorthy, G.; Sampurnam, S.; Manikandan, R.; Arulvasu, C.; Narayanan, V. Mat. Res. Exp., 2019, 6, 045003

21. Rafique, M.; Sadaf, I.; Rafique, M. S.; Tahir, M. B. Artif. Cells, Nanomedicine Biotechnol., 2017, 45(7), 1272-1291.

22. Molla, A.; Sahu, M.; Hussain, S. J. Mater. Chem. A., 2015, 3, 15616-15625.

23. Jha, M.; Shimpi, N. G. Nano-Structures and Nano-Objects., 2018, 16, 234-249.

25. Sahoo, A.; Patra, S. A. ACS Appl. Nano Mater., 2018, 1, 5169-5178.

26. Ghosh, S.; Roy, S.; Naskar, J.; Kole, R. K. Sci. Rep., 2020, 10, 277.

27. Isa, N.; Lockman, Z. Environ. Sci. Pollut. Res., 2019, 26, 11482-11495.

28. Naseem, K.; Begum, R.; Wu, W.; Irfan, A.; Al-Sehemi, A. G.; Farooqi, Z. H. Catalytic Reduction of Toxic Dyes in the Presence of Silver Nanoparticles Impregnated Core-Shell Composite Microgels. J. Clean. Prod., 2019. 211, 855-864.

29. Suvith, V.S.; Philip, D. Spectrochim. Acta-Part A Mol. Biomol. Spectrosc., 2014, 118, 526-532.

29. Vanaja, M.; Paulkumar, K.; Baburaja, M.; Rajeshkumar, S.; Gnanajobitha, G.; Malarkodi, C.; Sivakavinesan, M.; Annadurai, G. Bioinorg. Chem. Appl., 2014.

30. Ismail, M.; Gul, S.; Khan, M. I.; Khan, M. A.; Asiri, A. M.; Khan, S. B. Green Process. Synth., 2019, 8(1) 118-127.

31. Ahammed, K.R.; Ashaduzzaman, M.; Paul, S.C.; Nath, M.R.; Bhowmik, S.; Saha, O.; Rahman, M.M.; Bhowmik, S.; Aka, T.D. SN Appl Sci., 2020, 2, 